\title{
TRANSFORMATIVE LEARNING EXPERIENCES OF PRE-SERVICE EARLY YEARS TEACHERS: INSIGHTS FROM A GREEK HIGHER EDUCATION DEPARTMENT
}

\author{
Athina Charissi ${ }^{i}$ \\ Dr., Adjunct Lecturer, \\ University of Ioannina, \\ Greece \\ $\&$ \\ Tutor-Counselor, \\ Hellenic Open University, \\ Greece
}

\section{Abstract:}

This study aimed to investigate the transformative learning experiences of university students, namely pre-service teachers from an Early Years University Department in Greece. A total of 127 students were involved. The data were collected by using the Learning Activities Survey (L.A.S.). The questionnaire is divided into four parts, consisting of closed and two open-ended questions (King, 2009). The basic research questions were: (a) What stages of perspective transformation students went through during their studies, (b) What educational experiences and what personal events that experienced during their studies contributed to their perspective transformation, and (c) What elements related to students' participation-presence at school contributed to change. It was noticed that critical reflection on assumptions, the third most important precursor step in fostering transformative learning, was one of the less common stages that students went through along with self-examination. Only 4 students went through all the stages of perspective transformation as described by Mezirow (2012). However, certain patterns of transformative learning experience were identified. The respondents were found to face disorienting dilemmas causing their awareness to be raised in terms of: (a) Previously held values, beliefs, points of view or expectations regarding children (b) Their role as early years practitioners and its impact on children, (c) The need to exceed taken for granted ideas and obsolete pedagogical perceptions and (d) The importance of self-awareness, personal growth, and empowerment. It was shown that specific educational/learning activities, especially those engaging their experience, their active participation, mutual understanding, support (between classmates or classmates and teacher) and cooperation as well as exercising theory in practice, triggered perspective transformation. These findings imply the need for cultivating a higher education learning environment that supports the practicing of strategies and the

i Correspondence: email athkouk@yahoo.gr 
development of skills that can help learner's transformation and promote a more sustainable, socially-just and fulfilling world.

Keywords: transformative learning, pre-service teachers, precursor steps, sustainable society, profession consciousness

\section{Introduction}

Within Higher Education context special emphasis should be given to teachers' education and their adequate preparation in order to deal with the complex school realities in which they will engage (Caruana, Woodrow \& Pérez, 2015; Charissi, 2017; Charissi, 2020; Raikou, 2019). Engagement in transformative learning experiences seems to be an important factor for the students' personal and professional development. Critical thinking and transformation should be at the focus of a fertile HE environment leading to optimal professional preparation. Such a learning environment should not be oriented only to the promotion of the official curriculum. It is necessary to support students in examining their taken-for-granted assumptions and habitual ways of thinking (Charissi, 2020; Raikou \& Karalis, 2016) so as to become more self-sufficient and aware practitioners. Accordingly, it is important that teacher educators "design learning experiences for teacher candidates in a way that seeks to transform their knowledge, skills and perceptions to that of professional teachers and in some circumstances that of change agents" (Caruana, Woodrow \& Pérez, 2015, pp. 26-27) because of their critical role in connection to children, families and the society as a whole.

\subsection{The Research Interest}

Teachers' ability to critically evaluate their assumptions and to exploit this process in their professional practice is acknowledged as a key-feature for any transformative learning process (Caruana, Woodrow \& Pérez, 2015; Filippidi, Fotopoulou \& Raikou, 2019; Raikou, Liodaki \& Karalis, 2016). It is important that higher education prepares teacher candidates to be critically aware of their beliefs and assumptions and capable of engaging in a transformation of perspectives in a way that "learning and the enactment of new actions can occur" (Caruana, Woodrow \& Pérez, 2015, p. 27). In this way they will be able to respond constructively to the challenges of the complex learning context in a rapidly changing postmodern world (Brock, Florescu \& Teran, 2012). Significant learning experiences which not only engage learners in learning but also have the potential for long term changes and for their personal, professional, and social development are essential (Charissi, 2020; Raikou \& Karalis, 2016).

Scholars from various scientific fields have emphasized the implications derived from the challenges inherent into a rapidly changing world and the need for governments, organizations, and institutions to adopt new approaches which facilitate transformative learning (Moore, 2005; Scheele, 2015). Education should play a pivotal role to this direction. Relevant literature examines "the possibility (the potential benefits, 
drawbacks, and implications) of shifting university education from the current model toward models for transformative learning and sustainability" (Moore, 2005, p. 76). Higher education is considered a diverse entity with a multiplicity of roles in society, beyond the traditional one of transmitting knowledge. Such roles refer to research, community outreach, technological innovation, and knowledge creation. Consequently, "understanding how to facilitate transformative learning is crucial to engendering adaptive change, developing broader meaning perspectives, and making life on the planet socially just, sustainable, and fulfilling" (Scheele, 2015, p. 5).

Previous research has investigated transformative learning theory in higher education. It was focused on the factors promoting transformative learning experiences or the basic steps that students undergo during this changing process (Brock, 2010; Deveci, 2014; Kumi Yeboah, 2012) including the kind of educational/learning experiences that lead to pre-service teachers' perspective transformation (Caruana, Woodrow \& Pérez, 2015). In Greece there has been an increased interest in transformative educational experiences in Early Childhood Higher Education (Gkagkanasiou, Liodaki \& Karalis, 2017; Liodaki \& Karalis, 2013; Raikou, Liodaki \& Karalis 2016; Raikou, 2019). Three studies that took place in Greece, under normal teaching circumstances (Gkagkanasiou, Liodaki \& Karalis, 2017; Liodaki \& Karalis, 2013) and unprecedented ones such as those emerged during Covid-19 pandemic (Charissi, Tympa \& Karavida, 2020), have incorporated the Learning Activities Survey (King, 2009) as a research tool and combined both qualitative and quantitative data.

Following the concerns and implications about the significance of enhancing transformative learning in higher education, this study was oriented at exploring the transformative learning experiences of the students from an Early Years Academic Context in Greece. More specifically, it aimed at investigating the extent to which transformative learning occurred for the students of an Early Years Learning and Care University Department during their studies and the educational/learning experiences that contributed to this direction. In this way, the present study may contribute to the knowledge derived from diverse tertiary education contexts in terms of supporting a fertile and enabling learning environment and create the opportunities for transformative learning.

\section{Theoretical Framework}

\subsection{Teachers' holistic profession development and transformative learning}

Transformative learning is considered an important process through which "being $a$ teacher of holistic profession" perception and attitude can be cultivated (Zhu \& Li, 2019). Development is the key-idea that runs teachers holistic profession consciousness. Critical reflection and rational discourse lay at the foundation of such a notion of development embedded within a transformative learning context (Zhu \& Li, 2019, p. 472). Through a transformative learning lens teachers are empowered in identifying the three basic components, "learning being professional" which refers to a transformative learning point 
of view, "teaching being professional" which refers to a transformative relationship point of view and "contenting being professional" which refers to a transformative context point of view (Zhu \& Li, 2019, pp. 474-475).

Teachers' holistic profession development is associated with "inevitable learning changes" in their frames of reference, "which shape a coherent subject of learning experience, including associations, concepts, values, feelings, conditioned responses" (Zhu \& Li, 2019, p. 475). Within this context, teachers' optimal preparation during their studies should take into consideration promoting and supporting a learning environment which may foster transformative learning experiences. Self-awareness, empathy, and listening are considered, due to their mutual understanding nature, three basic components of a transformative classroom which engages both teachers and learners and facilitates perspective transformation (Taylor \& Cranton, 2012).

Transformation theory refers to the adults' need to make sense of the meaning of their experiences (Mezirow, 2000). It is about a learning process which involves shifts and changes within our frames of reference including cognitive, affective and behavioral dimensions. Both assumptions and beliefs are considered as core components of our meaning structures based on which we interpret reality and organize our experience. They constitute frames of reference through which we communicate, interpret and act (Lintzeris, 2007; Mezirow, 2000). Critical reflection includes the acknowledgment of how our assumptions are shaped and how they limit the way we perceive, understand, and feel. It is also considered as a precondition for the transformation of our frames of reference (Brookfield, 2000; Lintzeris, 2007; Mezirow, 2000) for them to become "more inclusive, differentiated, permeable, and integrated" (Mezirow, 1991, p. 151).

Transformative learning is associated with experiences that foster the development of being critically aware of our beliefs and assumptions and capable of engaging in a transformation of perspectives (Mezirow, 2000). The process of perspective transformation includes ten stages which are, according to Mezirow's (2012, p. 86) most recent reference to them: 1 ) a disorienting dilemma, that is a situation, event or sequence of events that causes a discrepancy between previous assumptions and current experiences and as such, triggers the process of transformation 2) self-examination, 3) critical assessment of assumptions 4) recognition of a connection between one's discontent and the process of transformation, 5) exploration of options for new roles, relationships and actions, 6) planning a course of action, 7) acquiring knowledge and skills for implementing one's plans, 8) provisional trying of new roles, 9) building competence and self-confidence in new roles and relationships and 10) a re-integration into one's life on the basis of conditions dictated by one's new perspective. It is not necessary that adults go through these stages in a linear way (Kokkos, 2019) while the more stages they may go through, the more possibilities they have to reach perspective transformation (Brock, 2010). 


\section{Research Methodology}

\subsection{Aims and Objectives}

The purpose of this study was to investigate the transformative learning experiences of the students from an Early Years Academic Context in Greece, particularly those attending the $3^{\text {rd }}$, the $4^{\text {th }}$ year of their studies and those in process of graduating, that is completing their internship and thesis. Especially, the basic research questions were: (a)What stages of perspective transformation students went through during their studies, (b)What educational experiences and what personal events that experienced during their studies contributed to the students' perspective transformation, and (c) What elements related to students' participation-presence at school were that contributed to change.

\subsection{Participants and Method}

The students who participated in this study were 118 students from a University Department of Early Years Learning and Care in Greece. Specifically, the $17.8 \%(\mathrm{n}=21)$ enrolled the 3 rd year courses, the $25.4 \%(n=30)$ enrolled the $4^{\text {th }}$ year courses and the $56.8 \%$ $(n=67)$ were in process of graduating. Most of the students surveyed were women (92.4\%), while most respondents were between 21 and 24 years $(79,7 \%)$. Of the remaining participants $11.9 \%$ were $<21,5,9 \%$ were between $25-29$ years, $1,7 \%$ between $40-49$ years and $0.8 \%$ were $30-39$ years. Regarding their previous education, most participants (83.9\%) have graduated from Secondary Education while 12.7\% have entered the department after completing vocational education (Greek EPAL with a specialization at childcare) and 1 participant had a master's degree.

It is worth mentioning that $62 / 118$ that is (52.5\%) of the participants were engaged previously to and in parallel with this study in three innovative projects aiming to the development of critical reflection. One project was based on the systematic use of art for raising children's critical thinking and empathy about friendship and difference (Charissi, Tympa \& Karavida, 2019), the second, enhanced the incorporation of the educational autobiography as a critical reflection tool towards personal and professional development of pre-service early years practitioners (Charissi, 2020) and a third one consisted in the exploration of the use of a reflection journal activity during two psychology courses in terms of promoting students' reflection on their learning experiences.

This study used a mixed-method approach and was conducted within a perspective transformation interpretive paradigm (Mezirow, 1991). Quantitative as well as qualitative data were collected through Learning Activities Survey-L.A.S (King, 2009). The L.A.S was developed by Kathleen P. King and it helps to investigate the transformative learning in higher education (King, 2009). The confidentiality was guaranteed through answering the questionnaire anonymously. 


\subsection{Data sources}

To effectively investigate participants' perspective transformation and the factors contributing to it, it was decided to use King's validated instrument - Learning Activities Survey (King, 1997, 1998) which measures the 10 precursor steps of Transformative Learning, according to Mezirow's model. An adaptation of LAS in Greek has been realized within specific previous research studies (Gkagkanasiou, Liodaki \& Karalis, 2017; Liodaki \& Karalis, 2013). King is acknowledged as the researcher who developed quantitative tools for the purpose of measuring transformative learning and calibrated its occurrence (Brock, 2010). The questionnaire is divided into four parts, consisting of closed questions and two open-ended questions (King, 2009).

\subsection{Data analysis}

The closed-ended questions were collected and coded using an Excel spreadsheet to prepare the answers for data analysis. Answers to the close-ended questions were analyzed statistically using SPSS. The open-ended questions were undergone context analysis and were used to specify descriptively and further clarify participants' answers. More specifically, students were asked to reflect on and describe: (a) what exactly was it that happened and caused changes on their values, beliefs, points of view or expectations, and (b) (Thinking back to when they first realized that their views or perspective had changed) In which way their presence-participation at their school have contributed to the experience of change.

\section{Research findings}

The findings derived from the quantitative part of the questionnaire are presented in the sections below.

\subsection{Learning activities and personal life events during Higher Education Studies}

All students participating in the study were asked to mark which of the 19 learning activities and which of the 8 personal life events defined in the LAS questionnaire were part of their experience during their studies. Table 1 shows the results of the quantitative analysis:

Table 1: Learning activities in which students participated $(\mathrm{n}=118)$

\begin{tabular}{|l|c|c|}
\hline Learning activities & Frequency & Percentage \\
\hline Another student's support & 64 & $55.7 \%$ \\
\hline Your classmate's support & 13 & $11.3 \%$ \\
\hline A challenge from a teacher & 56 & $48.7 \%$ \\
\hline Your teacher's support & 39 & $33.9 \%$ \\
\hline Your advisor's support & 7 & $6.1 \%$ \\
\hline Class/group projects & 68 & $59.1 \%$ \\
\hline Verbally discussing your concerns or interests & 56 & $48.7 \%$ \\
\hline Writing about your concerns & 21 & $18.3 \%$ \\
\hline Term papers/essays & 54 & $47.0 \%$ \\
\hline
\end{tabular}


TRANSFORMATIVE LEARNING EXPERIENCES OF PRE-SERVICE EARLY YEARS TEACHERS: INSIGHTS FROM A GREEK HIGHER EDUCATION DEPARTMENT

\begin{tabular}{|l|c|c|}
\hline \hline Personal journal & 8 & $7.0 \%$ \\
\hline Self-evaluation in a course & 29 & $25.2 \%$ \\
\hline Nontraditional structure of a lesson & 29 & $25.2 \%$ \\
\hline Class activities or exercise & 69 & $60.0 \%$ \\
\hline Internship or collaboration in a group & 85 & $73.9 \%$ \\
\hline Lab experiences & 78 & $67.8 \%$ \\
\hline Deep and concentrated thought & 23 & $20.0 \%$ \\
\hline Personal reflection & 37 & $32.2 \%$ \\
\hline Personal learning assessment & 44 & $38.3 \%$ \\
\hline Assigned readings & 50 & $43.5 \%$ \\
\hline
\end{tabular}

According to the results of the quantitative analysis presented in Table 1 the activities which involved students at a higher grade were: Internship or collaboration in a group (73.9\%), lab experiences (67.8\%), class activities or exercises prepared (60.0\%), class/group projects (59.1\%), another student's support (55.7\%), a challenge from a teacher (48.7\%), verbally discussing your concerns or interests $(48.7 \%)$, their participation in term papers/essays (47.0\%) and in assigned readings (43.5\%).

As far as it concerns the major experiences in their personal life that took place in the course of their studies, the analysis showed that the ones experienced by most students was moving away from their permanent residence (58.0\%), having a relationship (34.0\%) and the death of a loved one (35\%) (Table 2).

Table 2: Personal life events $(\mathrm{n}=100)$

\begin{tabular}{|l|c|c|}
\hline Personal life events that took place during their studies & Frequency & Percentage \\
\hline Marriage & 2 & $2.0 \%$ \\
\hline Birth/adoption of a child & 2 & $2.0 \%$ \\
\hline Moving & 58 & $58.0 \%$ \\
\hline Divorce/separation & 9 & $9.0 \%$ \\
\hline Loss a job & 4 & $4.0 \%$ \\
\hline Change job & 11 & $11.0 \%$ \\
\hline Make a relationship & 34 & $34.0 \%$ \\
\hline Death of a loved one & 35 & $35.0 \%$ \\
\hline Something else & 1 & $1.0 \%$ \\
\hline
\end{tabular}

\subsection{Perspective transformation}

Regarding the stages of perspective transformation, it turns out that the students (on average) went through 3.5 stages. The disorienting dilemma, that is, the challenges they encountered regarding the perceived social roles seems to be the most common stage that students went through. Table 3 demonstrates the stages of perspective transformation that they have undergone during their studies: 
TRANSFORMATIVE LEARNING EXPERIENCES OF PRE-SERVICE EARLY YEARS TEACHERS: INSIGHTS FROM A GREEK HIGHER EDUCATION DEPARTMENT

Table 3: Stages of Perspective Transformation $(n=118)$

\begin{tabular}{|l|c|c|}
\hline Stages of Perspective Transformation & Frequency & Percentage \\
\hline 1.a Disorienting dilemma (about actions) & 43 & $36.8 \%$ \\
\hline 1.b Disorienting dilemma (social roles) & 60 & $51.3 \%$ \\
\hline 2.a Self-examination (questioned world view) & 15 & $12.8 \%$ \\
\hline 2.b Self-examination (maintained world view) & 7 & $6.0 \%$ \\
\hline 3. Recognized discontent shared & 25 & $21.4 \%$ \\
\hline 4. Explored new roles & 37 & $31.6 \%$ \\
\hline 5. Critically reflected on assumptions & 10 & $8.5 \%$ \\
\hline 6. Tried on new roles & 36 & $30.8 \%$ \\
\hline 7. Planned action roles & 45 & $38.5 \%$ \\
\hline 8. Acquired knowledge/skills & 49 & $41.9 \%$ \\
\hline 9. Built confidence & 28 & $23.9 \%$ \\
\hline 10. Reintegrated to life & 46 & $39.3 \%$ \\
\hline 11. None of these & 8 & $6.8 \%$ \\
\hline 12. All the stages & 4 & $3.4 \%$ \\
\hline
\end{tabular}

Table 3 shows that most students (88.1\%) went through the first stage of perspective transformation, that is, the disorienting dilemma regarding their ideas about the perceived social roles (51.3\%) and about their actions (36.8\%). The next most common stages that students went through refer to the acquisition of the necessary knowledge and skills for implementing new plans $(41.9 \%)$, the reintegration into one's life because of conditions dictated by one's new perspective $(39.3 \%)$ and the planning of a course of action $(38.5 \%)$. Furthermore, $31.6 \%$ of the students went through the exploration of options for new roles, $30.8 \%$ the trying on of new roles, relationships, and actions, while $23.9 \%$ experienced building of competence and $21.4 \%$ recognized that their discontent and the process of transformation were shared and that others have negotiated a similar change. The less common stages that the participants went through were selfexamination with feelings of guilt or shame and the consequent decision to question their world view (12.8\%), critical reflection on assumptions $(8.5 \%)$ and self-examination with feelings of guilt or shame and the consequent decision to maintain their world view $(6.0 \%)$. Finally, $6.8 \%$ of the students didn't go through any of these stages and $3.4 \%$ of the students went through all stages.

\subsection{Experiences that influenced perspective transformation}

It is worth noticing that $39,5 \%(n=45)$ of the students stated that they had some kind of educational experience which changed their views, perceptions or beliefs while 4 students $(0.03 \%)$ didn't answer. Furthermore, $73.6 \%$ of those students were led to perspective transformation because of the influence that they acquired from a specific person during their studies and specifically from: (a) The motivation from a teacher $(61.4 \%),(b)$ The support from a teacher (34.1\%) and (c) The support from another student $(31.8 \%)$. 
The changes students experienced were impacted by their educational-learning experiences at a $94.3 \%$. According to the results there were certain learning activities which helped the students' perspective transformation as the table 4 shows.

Table 4: Learning activities contributing to perspective transformation $(n=45)$

\begin{tabular}{|l|c|c|}
\hline Learning activities & Frequency & Percentage \\
\hline 1. Class/group projects & 28 & $57.1 \%$ \\
\hline 2. Class activity/exercise & 26 & $53.1 \%$ \\
\hline 3. Verbally discussing your concerns & 27 & $55.1 \%$ \\
\hline 4. Internship or co-op & 33 & $67.3 \%$ \\
\hline 5. Writing about your concern & 10 & $20.4 \%$ \\
\hline 6. Lab experience & 32 & $65.3 \%$ \\
\hline 7. Term papers/essays & 13 & $26.5 \%$ \\
\hline 8. Deep, concentrated thought & 6 & $12.2 \%$ \\
\hline 9. Personal journal & 6 & $12.2 \%$ \\
\hline 10. Personal reflection & 18 & $36.7 \%$ \\
\hline 11. Self-evaluation in a course & 14 & $28.6 \%$ \\
\hline 12. Personal learning assessment & 16 & $32.7 \%$ \\
\hline 13. Nontraditional structure of a course & 11 & $22.4 \%$ \\
\hline 14. Assigned readings & 11 & $22.4 \%$ \\
\hline 15. Something else & 0 & $0 \%$ \\
\hline
\end{tabular}

More specifically, Table 4 shows that, regarding their change, students were mostly impacted by internship or cooperation within a group $(67.3 \%)$, lab experiences $(65.3 \%)$, class/group projects (57.1\%), verbally discussing their concerns or interests $(55.1 \%)$, class activities or exercises prepared (53.1\%). It is, also, interesting that next most common answers refer to personal reflection (36.7\%) and personal learning assessment $(32.7 \%)$, a finding that can be attributed to their engagement in innovative projects which presuppose self and peer-reflection, critical and creative thinking.

At a $54.5 \%$ students $(n=45)$ have experienced an important personal change event that helped their perspective transformation. The most popular events which took place in the participant's lives during their studies were: (a) The death of a loved one (43.3\%), (b) The moving from their permanent residence $(36.7 \%)$ and (c) The relationship that made with someone else $(23.3 \%)$

The findings derived from the qualitative part of the questionnaire are presented in the sections below.

\subsection{Reflections on experiences that contributed to change}

As far as it concerns the question what exactly was it that happened and caused change, most of the students who undergone some kind of change describe a process of enrichment both at a theoretical and practical/experiential level. Through their comments we can see that it was their participation to certain educational activities and innovative projects, that made them to revise: 
(a) Previously held values, beliefs, points of view or expectations regarding children and their balanced development:

"The project of educational autobiography, the workshops and the practice contributed to my change due to the recall of emotions and events in my life and the contact and interaction with the children."

"Through this school I started to think more maturely and to understand the value that young people have in our society and how I will be able to contribute properly to create a fully prepared person with the right values."

(b) Their role as early years practitioners and its impact on children:

"My view has changed about what a preschool teacher is, what exactly children need in that age, how the family and society play a key role in their development and all this as a whole later in society."

"I realized that every move I make can affect children to a great extent."

(c) The need to exceed taken for granted ideas and obsolete pedagogical perceptions:

"The new knowledge I gained, as well as the experiences that the teachers shared with us, pushed me to reconsider some of my beliefs. This is because the knowledge I have received in the past was either based on anachronistic perceptions or wrong. My critical thinking was reinforced, and the stimuli I received helped me to change my course of thought, values and views."

"After my practice I realized that many educators had similar views mainly regarding the treatment the punishment of children and I decided that I do not want to take any of them as an example because it only had negative results."

(d) The importance of self-awareness, personal growth, and empowerment:

"My expectations for the future became higher. I consider my future full of opportunities that I can conquer with continuing education and effort. My studies triggered my interest to attend seminars and projects, which greatly enrich my resume and experience."

"I started to believe in myself. After my experience at the preschool settings, I realized that you must constantly change because you have to deal with different situations. You must not be afraid and accept every challenge." 
When students were asked to reflect on their participation-presence at the school and its contribution to their perspective transformation they were mostly focused on the contribution of elements such as their engagement in reflection, the practical experience gained, the exchange of ideas and sharing of feelings, the development of personal and professional awareness and in general, a process of personal development towards a more mature way of thinking and acting. Here are some representative students' comments:

"I experienced a certain reflection experience. My participation after this reflection process was more conscious and I realized how much I like my profession."

"I became better, I feel that now I realize the content of my work."

"I was personally developed because of the daily contact with different people and the exchange of different and new views on various everyday issues and concerns."

"I learned to treat children differently in kindergarten, trying to see what is behind some of their behavior and not as if everything is the same."

"It has to do with the fact that I realized that we must always show our feelings, discuss them and constantly evolve for the better."

\section{Discussion}

This section discusses the findings of the present study which aimed at investigating the transformative learning experiences for the students from an Early Years Academic Context in Greece. More specifically, it was focused at exploring: (a) The extent to which transformative learning occurred for the students of an Early Years Learning and Care University Department during their studies, (b) The educational experiences and the personal life events during their studies that contributed to their perspective transformation, and (c) Students' evaluation of the elements related to their participationpresence at school that contributed to change.

Based on the results of the previous section, $51.3 \%$ of the students experienced, during their studies, a disorienting dilemma regarding the perceived social roles, which coincides with the first of the 10 precursor steps of perspective transformation and transformative learning (Mezirow, 2012). It also corresponds to the inherent to their profession challenge, to be able to deal with the complex and changing school, family and social realities and become more self-sufficient practitioners. According to transformative Learning, the process of transformation includes the potential for those engaged in it to critically re-examine and reshape their frames of reference in a more functional way, in order to become more open, diverse and ready for change (Mezirow, 1991, 2007). The first precursor step is considered as the starting point or "the 'root cause»' which 
triggers/motivates the student to question the already existing frame of reference" (Gkagkanasiou, Liodaki \& Karalis, 2017, p. 438).

On the other hand, critical reflection on assumptions, the third most important precursor step in fostering this kind of learning, was one of the less common stages that students went through (8.5\%) along with self-examination. However, relevant literature supports that tertiary education could and should play a crucial role in preparing university students and future professionals to grow and adapt to a rapidly changing world by promoting a learning environment that supports long-term change and the practice of skills such as critical reflection and sharing of experiences (Brock, 2010; Deveci, 2014; Kumi Yeboah, 2012). Promotion of transformative learning in the university context has the potential to multiply the benefits for the person, the society, and the planet (Moore, 2005; Scheele, 2015).

Further analysis showed that, on average, students went through 3.5 stages of perspective transformation during their studies even reaching the final stage $(39.3 \%)$ which refers to the reintegration of the new ways of behaving and acting to everyday life as a consequence of the transformative process. It is worth noticing that two other studies (Gkagkanasiou, Liodaki \& Karalis, 2017; Liodaki \& Karalis, 2013) conducted in a Department of Educational Science and Early Childhood Education in Greece, within a 4year period of studies, using King's evaluation tool, showed that their students went through 3.5 and 4.5 stages respectively. In comparison, the result of the present study (3.5 stages) is equivalent. However, the small amount of critical reflection, makes us thing that only few of them engaged in in-depth examination of the premises of their assumptions which is the key-issue for the realization of transformation (Mezirow, 2000). The influence from a specific person is evident. It is worth mentioning that from the $39.5 \%$ of the students who stated that they had some kind of educational experience which changed their views, perceptions or beliefs, $73.6 \%$ were led to perspective transformation because of the influence they acquired from a specific person, that is from the motivation from their teacher $(61.4 \%)$, the support from their teacher $(34.1 \%)$ and the support from another student $(31.8 \%)$. These results stress the importance of a supporting group in terms of personal contact and interaction with teachers and classmates. They are also in alignment with the finding that there were certain learning activities which facilitated a process of perspective transformation such as internship or cooperation within a group $(67.3 \%)$, lab experience $(65.3 \%)$, class/group projects $(57.1 \%)$, verbally discussing their concerns (55.1\%) and class activity/exercises (53.1\%), that is, activities which presuppose active participation, mutual understanding, and cooperation.

In total, the changes that students went through were impacted by their educational/learning experiences at a 94.3\% while we can't ignore the contribution of personal life events at a $54.5 \%$. According to the results, among the most popular life events which took place in the participant's lives during their studies were: (a) The death of a loved one $(43.3 \%)$, (b) The moving from their permanent residence $(36.7 \%)$ and (c) The relationship that made with someone else $(23.3 \%)$. 
Results from the qualitative section of the questionnaire, which aimed at further highlighting students' reflections about what exactly was it that happened and caused changes on their values, beliefs, points of view or expectations, and the overall contribution of their participation to this process of change, reveal a procedure of increased awareness about: (a) Previously held values, beliefs, points of view or expectations regarding children, (b) Their role as early years practitioners and its impact on children, (c) The need to exceed taken for granted ideas and obsolete pedagogical perceptions and (d) The importance of self-awareness, personal growth and empowerment. They attribute this procedure to their enrichment both at a theoretical and practical/experiential level during their studies while they also characterize it as a process of maturation both at a personal and professional level based on increased reflection, empathy, and mutual exchange. According to both quantitative and qualitative findings, their internship and engagement in innovative projects aiming to the development of critical reflection contributed to this process.

These findings are in alignment with the discussions about the need to rethink tertiary education in terms of promoting "models for transformative learning and sustainability" (Moore, 2005, p. 76). Due to its multiplicity of roles, university education could form a facilitating context towards a more socially just and sustainable life in planet (Scheele, 2015) by enabling critical reflection, broadening of meaning perspectives, and functional adaptation, also key features of teachers' holistic profession consciousness (Zhu \& Li, 2019).

\section{Conclusion}

The findings indicate that during their 4year studies pre-service teachers from an Early Years Learning and Care Department in Greece, experienced disorienting dilemmas concerning taken-for-granted assumptions about habitually internalized social roles regarding children, their profession as Early Years Practitioners and its impact on children, families, the society as a whole and the need to constantly evolve through theory and practice. Although they did not pass all the stages of perspective transformation during their studies (3.5 stages on average), it was shown that specific educational/learning activities, especially those engaging their experience, their active participation, mutual understanding, support (between classmates or classmates and teacher) and cooperation as well as exercising theory in practice, triggered perspective transformation, a 10 steps process leading to transformative learning. Educational/learning experiences impacted this change at a $94.3 \%$ while personal life events contributed at a proportion of $54.5 \%$. According to the results, there had been some shifts concerning students' way of thinking, feeling, and acting but only 4 of the 118 students who participated in the study have gone through all steps of transformative learning as defined by Mezirow and described at the theoretical framework. A reorientation of Higher Education learning experiences in terms of their transformative and critical reflection dynamics should be considered if we want to fully prepare self- 
sufficient and informed teacher professionals that will contribute to a more sustainable, socially-just and fulfilling world.

\title{
Conflict of Interest Statement
}

The authors declare no conflicts of interests.

\begin{abstract}
About the Author
Dr. Athina Charissi is an adjunct Lecturer at the University of Ioannina, Greece and Tutor-Counselor at the Hellenic Open University. She has a PhD from the Department of Philosophy, Education \& Psychology, University of Ioannina, Greece, and a Master of Education from the same Department. Her basic studies are in Philosophy, Education and Psychology, with a specialization in Psychology. She is a Certified Adult Educator and participates in research projects related to the multilateral phenomenon of human learning including teachers' personal and professional development with an emphasis on the promotion of critical reflection and transformative learning. Her research and publications in international and Greek conferences, as well as in scientific journals, focus on Pedagogy and Psychology, Adult Education/Lifelong Learning, Personal and Professional Development of Teachers.
\end{abstract}

\section{References}

Brookfield, S. D. (2000). Transformative learning as ideology critique. In J. Mezirow \& Associates (Eds.), Learning as transformation. Critical perspectives on a theory in progress (pp. 125-150). San Francisco, CA: Jossey-Bass.

Brock, S. (2010). Measuring the Importance of Precursors Steps to Transformative Learning. Adult Education Quarterly, $60 \quad$ (2), $122-142$. https://doi.org/10.1177/0741713609333084

Brock, S., Florescu, I., \& Teran, L. (2012). Tools for Change: An Examination of Transformative Learning and Its Precursor Steps in Undergraduate Students. International Scholarly Research Network ISRN Education, Volume 2012[Article ID 234125], 1-5. https://doi.org/10.5402/2012/234125

Caruana, V., Woodrow, K., \& Pérez, L. (2015). Using the Learning Activities Survey to Examine Transformative Learning Experiences in Two Graduate Teacher Preparation Courses. InSight: A Journal of Scholarly Teaching, 10, 25-34. https://doi.org/10.46504/10201502ca

Charissi, A. (2017). From Critical Consciousness to Change? The Experience of a Mutual Learning Group of Teachers. Doctoral Dissertation. University of Ioannina, Greece. [in Greek].

Charissi, A., Tympa, E., \& Karavida, V. (2019). Contribution of Systematic Exploration of Artworks in Raising Children's Critical Thinking and Empathy about Friendship 
and Difference through Early Years. International Journal of Education, 11(4), 35-47. https://doi.org/10.5296/ije.v11i4.15857

Charissi, A. (2020). The Educational Autobiography as a Critical Reflection Tool towards Personal and Professional Development of Pre-service Early Years Practitioners. $\begin{array}{lllll}\text { European Journal of Education } & \text { Studies, } & 7(2),\end{array}$ https://zenodo.org/record/3718604\#.YX0RptSLSt8

Charissi, A., Tympa, E., \& Karavida, V. (2020). Impact of the Covid-19 disruption on university students' perceptions and behavior. European Journal of Education Studies, 7(11), 222-238. https://dx.doi.org/10.46827/ejes.v7i11.3348

Deveci, T. (2014). The Transformative Learning Experiences of Learners of English as a Foreign Language at a University Preparatory Programme. Transformative Dialogues: Teaching E Learning Journal, 7[3], 1-19.

Filippidi, A., Fotopoulou, V. S., \& Raikou, N. (2019). Investigating School Placement as an Opportunity for Reflection for Prospective Teachers. European Journal of Alternative Education Studies, 4(2), 60-71. https://dx.doi.org/10.46827/ejae.v0i0.2662 Gkagkanasiou, A., Liodaki, N., \& Karalis, T. (2017). Transformative Learning Theory and Educational Experiences in Higher Education: The case of a Department of Education in Greece during a four years period. In I. M. Katsillis, Confronting Contemporary Educational Challenges Through Research, International Conference on Educational Research Proceedings, Patras 30 June-2 July, 2017, pp. 435-441. [in Greek]

King, K. P. (1997). Examining activities that promote perspective transformation among adult learners in adult education. International Journal of University Adult Education, 36(3), 23-37.

King, K. P. (1998). A guide to perspective transformation and learning activities: The Learning Activities Survey. Philadelphia: Research for Better Schools, Inc.

King, K. P. (2009). The handbook of the evolving research of transformative learning based on the learning activities survey. Charlotte, NC: Information Age Publishing, Inc.

Kokkos, A. (2019). Introduction. In A. Kokkos \& Associates (Eds.). Expanding Transformation Theory (pp. 13-39). Athens: Hellenic Adult Education Association. [in Greek]

Kumi, Y. A. (2012). Factors that Promote Transformative Learning Experiences of International Graduate-Level learners (2012). Graduate Theses and Dissertations. https://digitalcommons.usf.edu/etd/4113

Lintzeris, P. (2007). The significance of critical reflection and discourse in Jack Mezirow's theory of transformative learning. Athens: Hellenic Adult Education Association. [in Greek] Liodaki, N., \& Karalis, T. (2013). Educational Experiences and Transformative Learning in Higher Education in Greece: A Case Study with Student Teachers. International Journal of Education, 5(2), 75-85. https://doi.org/10.5296/ije.v5i2.3282

Mezirow, J. (1991). Transformative dimensions of adult learning. San Francisco: Jossey-Bass. 
Mezirow, J. (2000). Learning to think like an adult. Core concepts of transformation theory. In J. Mezirow, \& Associates (Eds.), Learning as transformation. Critical perspectives on a theory in progress (pp. 3-33). San Francisco, CA: Jossey-Bass.

Mezirow, J. (2012). Learning to Think Like an Adult. Core Concepts of Transformation Theory. In E. W. Taylor, P. Cranton \& Associates (Eds.). The Handbook of Transformative Learning: Theory, Research and Practice (pp. 73-95). San Francisco, CA: Jossey-Bass.

Moore, J. (2005). Is Higher Education Ready for Transformative Learning? A Question Explored in the Study of Sustainability. Journal of Transformative Education, 3(1), 7691. https://doi.org/10.1177/1541344604270862

Raikou, N., \& Karalis, T. (2016). Adult Education and Higher Education - A Focus on Transformative Learning in Universities. International Education \& Research Journal[IERJ], 2(4), 19-22.

Raikou, N., Liodaki, N., \& Karalis, T. (2016). Critical reflection and dialogue on preservice teachers' practicum, In D. Andritsakou, \& E. Kostara, The Role, Nature and Difficulties of Dialogue in Transformative Learning, Proceedings of the 2nd Conference of ESREA's Network "Interrogating Transformative Processes in Learning and Education: An International Dialogue" (307-315). Athens, Greece: ESREA \& Hellenic Adult Education Association.

Raikou, N. (2019). Teacher education at the forefront: long-term study through the prism of university pedagogy and transformative learning theory. European Journal of Education Studies, 6(3), 88-102. https://doi.org/10.5281/zenodo.3243470

Scheele, P. R. (2015). Transformative learning in higher education: Praxis in the field of Leadership change. Journal of Transformative Learning, 3(1), 5-12.

Taylor, E. W., \& Cranton, P. (2012). Reflecting Back and Looking Forward. In E. W. Taylor, P. Cranton and Associates (Eds.), The Handbook of Transformative Learning: Theory, Research and Practice (pp. 555-573). San Francisco, CA: Jossey-Bass.

Zhu, X., \& Li, Y. (2019). Being a Teacher of Holistic Profession: A Perspective of Transformative Learning. Beijing International Review of Education, 1(2-3), 472-487. doi: https://doi.org/10.1163/25902539-00102004. 
Creative Commons licensing terms

Authors will retain the copyright of their published articles agreeing that a Creative Commons Attribution 4.0 International License (CC BY 4.0) terms will be applied to their work. Under the terms of this license, no permission is required from the author(s) or publisher for members of the community to copy, distribute, transmit or adapt the article content, providing a proper, prominent and unambiguous attribution to the authors in a manner that makes clear that the materials are being reused under permission of a Creative Commons License. Views, opinions and conclusions expressed in this research article are views, opinions and conclusions of the author(s). Open Access Publishing Group and European Journal of Alternative Education Studies shall not be responsible or answerable for any loss, damage or liability caused in relation to/arising out of conflict of interests, copyright violations and inappropriate or inaccurate use of any kind content related or integrated on the research work. All the published works are meeting the Open Access Publishing requirements and can be freely accessed, shared, modified, distributed and used in educational, commercial and non-commercial purposes under a Creative Commons Attribution 4.0 International License (CC BY 4.0). 